\title{
1. Conceptualizing community within the public goods paradigm
}

\section{DEFINITION OF A PUBLIC GOOD}

In the discipline of economics, a critical distinction is made between "private" and "public goods." The costs and benefits of paying for private goods is assumed to be determined by a variety of market forces, such as supply and demand, albeit with considerations of institutional protections, such as third party enforcement of contracts. Economists recognize, however, that there is another class of goods whose benefits are non-excludable and non-rivalrous where everyone will receive benefits from the goods (Samuelson 1954). In our contemporary world, fire and police protection as well as national security are commonly accepted as public goods, although typically there are fierce public policy debates about the quality, cost and mechanisms to pay for these goods.

\section{Mancur Olson and the Principle of Group Size and Collective Action}

The critical issue is how to pay for the costs of goods that everyone will enjoy. Mancur Olson's (1971) classic work, The Logic of Collective Action, argues that there is a fundamental difference in the way that public goods are paid for in small groups and what he terms "large latent groups." He notes that:

certain small groups can provide themselves with collective goods without relying on coercion or any positive inducements apart from the collective good itself. This is because in some small groups each of the members, or at least one of them, will find that his personal gain from having the collective good exceeds the total cost of providing some amount of that collective good; there are members who would be better off if the collective good were provided, even if they had to pay the entire cost of providing it themselves, than they would be if it were not provided. (1971: 33-4)

Olson goes on to say, however, that:

the larger the group, the smaller the fraction of the total group benefit that any person acting in the group interest receives, and the less adequate the reward for any group-oriented action, and the farther the group falls short of getting an optimal supply of the good, even if it should get some. (1971: 48) 
This fundamental difference between small and large groups explains why large groups typically rely either on coercion or selective incentives to pay for the costs of collective goods that will benefit all of their members. In addition to user fees, the costs of most municipal, state and national public goods such as highways, schools and other "public services" in contemporary democracies are paid for through citizen initiated coercive mechanisms, such as bond issues or taxes imposed by elected legislative bodies. Similarly, large industrial unions in the United States achieved legitimacy to pursue collective bargaining for their members only when the Wagner Act, upheld by the US Supreme Court in 1937, required that if a majority of individuals in the workplace vote for union representation then all workers would have to pay union dues (Olson 1971: 66-97). Professional organizations pay for the costs of the public good of lobbying for collective interests by providing individual members with some selective benefit, such as insurance or access to support services (Olson 1971: 132-68).

\section{Gemeinschaft and Gesellschaft}

The fundamental difference in the way that small and large groups pay for the cost of their respective collective goods is especially important in understanding the different ways in which the "community problem" is to be defined. In Tonnies's (2001) classic typology, the gemeinschaft, or community, is approximated most closely today in small, isolated rural places where individual behavior is severely restrained within clearly defined informal institutional structures of expectations that are operationalized in specific norms, values and social roles (Wuthnow 2018). Gesellschaft, or civil society, is a much larger grouping of individuals with a diverse set of interests that are reconciled through complex formal institutional structures. This ideal type is approximated most closely by rapidly diversifying metropolitan areas in the United States and Western Europe. The ways in which these different types of human groupings have been organized create substantial variations in their respective ability to deal with globalization, which will be described in detail in later chapters.

At this juncture, however, there is another aspect of Olson's insights into how collective action is achieved in large latent groups that is crucial to understanding and dealing with community challenges today. Specifically, the effects of declining communities and zero-sum inter-community conflict are felt not only by those who live in these places but by a larger public who live outside of them. This includes the spillover effects of social and personal disorganization, such as opiate addiction and suicide that generate considerable local, state and federal taxpayer costs for law enforcement, health and mental health, increased support for authoritarian populist movements, with 
its attendant costs of loss of support for democratic institutions and diversion of political discourse from dealing with substantive challenges associated with globalization, such as job training and infrastructure. The goal of this book is to analytically define community issues as larger public goods issues. Historical accounts show that this is extremely difficult.

\section{HISTORICAL STRUGGLES TO DEFINE A PUBLIC GOODS PROBLEM}

The acceptance of something as a public good requires two steps. The first is the acceptance that something affects the larger collectivity or public in a way that no one can be excluded. The second is acceptance that some formal institutional (i.e., coercive) mechanism must be employed so that members of the collectivity will pay for the costs of achieving that good.

\section{Fire Protection, Pure Food and Drug Act, and Public Schools}

Although volunteer fire brigades operated in the United States in the American colonies in the 1600s, it was not until the middle of the 19th century, around the time of the Civil War, that city governments funded fire departments, with salaried employees (Henzler 2011). The notion that regulating the manufacture, sale or transportation of adulterated or mislabeled food and drugs was not accepted as a public good in the United States until the passage of the Pure Food and Drug Act in 1906, which paved the way for the US Food and Drug Administration (FDA), and eventually a number of other government regulatory agencies (Young 1989). Although the Massachusetts Bay Colony mandated a minimum level of primary school public education for all of its citizens in 1642, it was not until 1918 that mandatory public elementary school education was required in all of the states of the United States (Neem 2017).

\section{The Wagner Act and Workers' Right to Collective Bargaining}

Until 1937, the sacred place of the "individual contract" in American culture was an obstacle against the notion that individual workers were at a distinct disadvantage vis-à-vis a small group of employers unless they somehow could have access to a provision that required all workers to pay dues to a union, in order to obtain a collective benefit. Nonetheless, in 1937, after many previous failures, during the depths of the Great Recession and the ascension of the New Deal coalition under Franklin Delano Roosevelt, the Wagner Act that established the National Labor Relations Board and guaranteed the right of workers to vote for collective representation - if a majority of workers in a firm voted for union representation all of their fellow workers were required to pay 
union dues - was upheld by the Supreme Court. The Court's decision in this case resulted in a major institutional shift in the American economy, not only in creating countervailing power for workers vis-à-vis industrialists but also in changing long-held American cultural values and norms (Olson 1971: 66-97).

\section{Health Care}

Another area of ideological resistance to defining something as a public good is found in the long struggle for universal health care in the United States. The definition of access to universal health care as a public good was realized in almost all Western industrialized nations by the middle of the 20th century. The main holdout among these wealthy nations has been the United States, despite the indisputable fact that American health care outcomes and costs far outweigh those of their Canadian and European counterparts (Sawyer and Gonzales 2017).

\section{COMMUNITY ISSUES AS LARGER PUBLIC GOODS PROBLEMS}

If we define the building and maintenance of resilient communities as having serious spillover effects not only for the members of individual communities, but for the larger society as well, then it is essential to conceptualize community-building as a national and, increasingly, global public good. Most important, the definition of community-building as a broader issue than the individual community itself provides a rationale for formal institutional adjustments and the resources to deal with these issues. In later chapters, we will examine specific ways in which institutional adjustments can be effectively employed to build resilient communities in an age of increasing globalization and specific formal institutional arrangements that can overcome these obstacles. At this juncture, however, it is critical that we fully understand why the fate of individual communities, even if they are some great physical and psychic distance removed from us, has serious consequences for the larger public in which we are a member. The scientific basis for this assertation is based on a growing number of empirical studies by social science researchers. Three areas in particular that have received considerable attention by researchers and public policymakers are: (1) the economic costs to the larger public that stem from the effects of weakened or dysfunctional communities on national workforce capacity, health, mental health and substance abuse problems; (2) how the loss of community attachment can lead to a mass society and populism; and (3) eventually to the weakening of long-standing institutions of liberal democratic society. 


\section{Community Effects on Personal Pathologies and Workforce Capacity}

The social science literature is steeped in research studies showing the effects of different types of communities and community attachments on physical and mental health, as well as occupational mobility and overall life chances. Durkheim's (2006) classic study showing that rates of suicide are associated with the weak attachment of individuals to groups has been confirmed by contemporary research (Breault 1986; Rowe and Kahn 1997). At the same time, other sociological studies have shown that attachments to certain types of communities can reinforce behaviors and outlooks that can become serious obstacles to individuals achieving success in education and employment. This is illustrated in William Foote Whyte's (1955) ethnographic study of Street Corner Society, in which one of the two main characters focuses most of his energy on athletic skills, like bowling and street corner language, that achieves status in the neighborhood, but which has very little value in achieving upward mobility. The other main character tries to improve his grammar, physical appearance and academic skills that are frowned upon on the street corner but facilitates his upward mobility into middle-class society. Norbert Wiley (1967) refers to the neighborhood attachment of the first character as "the ethnic mobility trap." More recent research by William Julius Wilson (1980) and Robert J. Sampson (2012) has shown the powerful effect of neighborhood community attachment on an individual's economic success in life.

The most convincing evidence of the causal effects of neighborhood context on life chances is found in the "Moving to Opportunity Experiment," the results of which were reported in an article in the American Economic Review (Chetty, Hendren and Katz 2016). This experiment randomly assigned poor families to receive a voucher that would enable them to move to a more affluent neighborhood, while a control group from the same poverty environment did not receive the vouchers and thus stayed in place. The most important finding of the study, which followed the life outcomes of the experimental and control groups over a number of years, was that children under the age of 13 who were in the experimental group - that is, their families moved to the better off neighborhood - did substantially better than the same age cohort in the control group in terms of college attendance, income and not living in a single parent household as adults. Moreover, the benefits for this cohort in the experimental group continued into the next generation. The authors summarize their findings as follows:

Our findings show that a simple model featuring linear childhood exposure effects coupled with a fixed disruption cost of moving to a distinctly different social environment can reconcile some of the key findings and debates in the literature on neighborhood effects. First, our results suggest that a substantial fraction of the 
systematic variation in economic outcomes across areas documented in observational studies that attempt to control for selection effects ... can indeed be explained by causal effects of neighborhoods. Since many low-income individuals observed in a given area have grown up in that area since an early age, childhood exposure effects of the type documented here would generate significant differences in mean outcomes across areas in observational data. The fact that MTO had no impact on adults' outcomes (irrespective of exposure time to lower-poverty areas in adulthood) implies that neighborhood effects operate primarily through "developmental" effects during childhood ... (Chetty, Hendren and Katz 2016: 899)

The "moving to opportunity" experiment is consistent with findings in Daniel Patrick Moynihan's mid-1960s report, The Negro Family: A Case for National Action, which focused on the structural causes of poor workforce capacity among urban African Americans right after the passage of the Civil Rights Act of 1964. The historical de facto segregation of African Americans in northern cities, both in terms of housing and employment, had the effect of weakening family structures, which, in turn, meant the concentration of successive generations of single parent households, weak male role models and the corresponding enculturation of youth in attitudes and behaviors that were not conducive to upward mobility, such as delinquency and poor school performance (Rainwater and Yancey 1967).

A half century later, the causal relationship between local community economic opportunities and the "tangle of pathology" is found among a significant portion of the white population in the United States. The documentation for this relationship is found in an analysis of the data in the 2019 report by the Centers for Disease Control and Prevention (CDC) that leads with the startling finding that overall life expectancy in the United States declined in successive years, 2015 and 2016. Overall, US life expectancy was two years shorter than that of the 35 OECD (Organisation for Economic Co-operation and Development) high-income countries, below Britain, France and Germany, but closer to Turkey and Costa Rica. The proximate causes of the decline in life expectancy in the United States is clearly identified as the increase in opiate addiction, smoking, obesity and suicide (Bernstein and Ingraham 2017).

A critical finding is that these community-related personal pathologies, and their associated negative effects on life expectancy, are found increasingly in isolated rural communities, which have extremely high rates of opiate addiction and suicides (Khazan 2017; Maciag 2018). Ironically, these communities also had the highest proportion of residents who voted for Trump in the 2016 election (Bor 2017). This is a critical point that we will address later in this chapter. Nonetheless, all of these studies indicate that personal pathologies are not only generated in the traditional focus in urban slums, but also in communities that once were heralded as the prototype of a presumably wholesome "American way of life." 
As Moynihan found in his report, eliminating discriminatory laws, by itself, would not solve the problem of integrating urban African American men into the labor force; rather, he argued that greater attention should be paid to creating institutions - that is, the War on Poverty programs - that would provide government-funded job skill training programs, from which African Americans were often excluded at that time. By the same token, the elimination of "unfair trade" will not, by itself, solve the problems of poor job skills among rural Americans. In fact, in some ways, many of the structural conditions in rural areas are worse than those in poor areas in the central cities. This is seen, for example, in the absence of broadband internet connections, as well as poorer levels of access to health care in many rural places (Reinberg 2019). Another study found that breast cancer patients in rural communities were, on average, diagnosed at a later stage than patients in inner city neighborhoods, even when controlling for race and class (Williams et al. 2015).

The obvious inequities in physical infrastructure, be it lack of safe water in Flint, Michigan, or the absence of broadband in public schools in rural America, calls attention to ways in which public policy might be shifted to remedy these conditions. A recent overview of "empty places" in The Economist (2017) magazine proposed shifting some public funds away from individual transfer payments to building up declining infrastructure to improve workforce capacity - for example, higher pay to attract better teachers and broadband access for both children and adults - and thus improve the opportunities to attract high-paying jobs in the new high-tech economy. A comprehensive template for obtaining the tax revenue to achieve these objectives is outlined by Collier (2018), which we will examine in Chapter 6.

The isolation of individuals in urban ghettos or remote rural regions is associated with a lack of access to information about how to deal with life's exigencies, which, in turn, exacerbates the anxiety and loneliness that contributes to addictive behaviors, depression and suicide; but it also creates a barrier to accessing treatment, even when it is available. A study in a metropolitan area in Northeast Ohio in the 1970s, for example, found that African Americans were much less likely to be aware of and use free public services if they lived in neighborhoods that were highly segregated (Mueller and O'Brien 1986). Similarly, whites in homogeneous and isolated rural communities tend to have much smaller, denser and more kin-dominated social support networks than their counterparts in more diverse metropolitan regions (Marsden 1987; O'Brien, Hassinger and Dershem 1996). These structural characteristics of rural community helping networks generate especially challenging problems when major exogenous structural changes affect individuals' lives. Research shows that the ability to cope with life requires having the belief that one has strong ties with emotionally supportive individuals, but that the ability to cope with novel situations requires, in addition, some weak bridging ties (Woolcock 
and Narayan 2000) that can provide instrumental support, such as new information on ways to deal with unexpected problems. This might include, for example, where to find a job, how to build an effective collective action organization to deal with powerful entities that can cause adverse effects to one's local community, or how to access mental health services (Granovetter 1973; Lin 2001: 67-8; Tausig, O'Brien and Subedi 1992).

The small, dense, kin-dominated social support networks that are typically found in rural communities often create a barrier to accessing treatment, both from formal mental health services and informal support groups, such as Alcoholics Anonymous or Narcotics Anonymous meetings, than do the more diverse social support networks found in urban communities (Young, Grant and Tyler 2015). This appears to fit the situation that Thoits (1995) alerted us to, in which a highly dense, kin-dominated social support network does not fit the social psychological needs of the individual and thus may actually be an impediment to seeking out a support group that would be better able to help that person (Bernstein and Ingraham 2017; Khazan 2017; Maciag 2018).

The aforementioned findings help to explain why in a rapidly changing era when exogenous forces of globalization are continuously demanding change in order to maintain sustainability, rural communities that are highly homogeneous oftentimes are more vulnerable to inaction than are more diverse metropolitan communities. Richard Florida (2002) provides data to show that more diverse communities are more creative and entrepreneurial, which, in turn, means that they have a much greater capacity to adapt to exogenous changes, which requires altering the assumptions underlying traditional ways of thinking and behaving. Moreover, the social organizational and cultural supports for a traditional mindset that are found in homogeneous communities are very susceptible to demagogic appeals to return to an idealized earlier community. This was reflected in the 2016 American Presidential election, where a majority of rural voters were attracted to a reactionary populist message from candidate Trump, who promised to "Make America Great Again," despite the fact that many of these supporters were living in places that by objective standards were worse off, both economically as well as health- and mental health-wise than in metropolitan communities where voters were more likely to vote for Clinton (Bor 2017; Chokshi 2018; DelReal and Clement 2017).

It is important, however, to note that there is variability in the degree to which rural environments generate social pathologies, and that, in fact, some rural communities appear to produce environments that generate high levels of upward social mobility among their youth. In Chapter 5 we will elaborate in detail on the findings reported by Krause and Reeves (2017) showing that there are a number of specific institutional adjustments that are associated with building human capital in small communities and that these investments 
suggest policy strategies that could be employed across a larger swath of the American countryside.

At this point, our main focus is on conceptualizing the larger public goods associated with overcoming community dysfunction. The studies of community effects on personal pathologies in both urban and rural regions suggest that attention must be given to what are the unique features of those seemingly disparate types of communities that lend themselves to producing human beings with serious problems that not only affect their lives, and those of their immediate families and communities, but also generate severe economic costs for the larger society. The latter include national budget draining effects of medical and law enforcement costs, a decline in the capacity of the workforce to meet the technological challenges of globalization and the failure to provide the tax revenue to support an increasingly aging population. Ameliorating these trends constitutes a classic public goods challenge for the collectivity of taxpayers, who eventually pay for these costs.

\section{The Loss of Community, Mass Society and Populism}

Another major cost of the decline in community attachment, from a public goods perspective, is the creation of "mass society." Tocqueville's classic work on American civic life in the 1830s made much of the role of participation in local community organizations as a countervailing force to the "tyranny of the majority" (Tocqueville 2004, Volume II: 590-613). Skocpol (1997) points out this was in large measure a mutually reinforcing relationship between the institutions of the federal constitutional system and the cultural values and norms of grassroots participation in governance that was referred to in the introductory chapter of this book. Beginning sometime in the last part of the 20th century, however, surveys have found a decline in overall voluntary association membership, which is associated with the decline in overall social capital (Putnam 2015). Painter and Paxton (2014) found that even where membership in voluntary associations was not declining, there was a clear trend toward what they called "checkbook memberships," in which individuals joined organizations but did not have high levels of participation, and when they did participate it was only through monetary contributions.

There has been a decline in the percentage of adult Americans who are members of a church or synagogue from 70 percent in 1992 to 59 percent in 2014 (Pew Research Center 2015). During the same time period, union membership also declined from 12 million workers in the private sector in 1983 to 7.6 million in 2015. The percentage of unionized workers in the public sector actually increased during the same time period, from 5.7 million in 1983 to 7.2 million in 2015 , but the overall number of unionized workers in the United 
States declined from 20.8 million in 1983 to 11.1 million in 2015 (Dunn and Walker 2016).

An alarming long-term trend has been the increasing separation of individuals and households from interaction with others who have different points of view, both in terms of what kinds of media they watch to get information about current events and where they live. This produces what Bill Bishop (2009) calls The Big Sort. Not only is there a separation between individuals from different social classes or religious (or non-religious) affiliations but also a lack of interaction between persons with different political orientations. This results in a lack of empathy for others who think differently and reduces the social capital - trust and social networks - necessary to support constructive engagement on difficult issues. As noted earlier, Gordon Allport's central thesis, based on numerous studies of prejudice, is that equal status interaction between individuals in groups tends to increase tolerance, while lack of equal status interaction, or, as is increasingly the case, no personal interaction at all, will increase intolerance and hardening of ideological barriers between individuals who belong to more homogeneous collectivities (1958: 250-68).

The popular phrase, "the increased tribalism in American politics," does not reflect a growth in concerted collective action in an organizational sense. In fact, this polarization is highly correlated with an increasing number of individuals who are disconnected from any traditional organizational affiliations - churches, unions and voluntary associations - and who suffer from extreme anxiety and fear about a real or imagined loss of status.

The World Happiness Report (Helliwell, Layard and Sachs 2019) identifies a strong association between the overall level of subjective happiness in a country and the extent to which its citizens are socially connected to one another. High levels of social attachment are found in Finland, which received the highest ranking on subjective happiness for the second year in a row, followed by its Scandinavian neighbors, Denmark, Norway and Iceland. The report ranked the United Kingdom 15th and the United States 19th. A whole chapter of the report is devoted to "The Sad State of Happiness in the United States and the Role of Digital Media," noting that face-to-face interaction among Americans has declined substantially and that this is correlated with the decline in subjective indicators of happiness in recent years. This association is especially strong among American teenagers who have experienced a precipitous decline in social attachments along with a concomitant decline in personal happiness. The report notes that:

During the same time period that digital media use increased, adolescents began to spend less time interacting with each other in person, including getting together with friends, socializing, and going to parties. In 2016, iGen college-bound high school seniors spent an hour less a day on face-to-face interaction than GenX adolescents 
did in the late $1980 \mathrm{~s} . .$. Thus, the way adolescents socialize has fundamentally shifted, moving toward online activities and away from face-to-face social interaction. (Helliwell, Layard and Sachs 2019: chapter 5)

There is a truly frightening parallel between the conditions that gave rise to Fascism in Germany in the 1930s and the conditions that are giving rise to contemporary authoritarian movements that fall under the general rubric of "populism." In both cases, we can identify structural economic crises; in the Great Depression and the burdens of post-World War I reparations on the German people, while in the latter we can trace the growth of inequality and automation since the 1970s and its effect in dampening post-World War II optimism in Western countries. Nonetheless, the critical element in the rise of right-wing extremism in both instances is the sense among a growing mass of atomized, disconnected individuals that they have lost control over their own destiny. This created, both in the earlier and contemporary eras, an environment in which demagogues can provide promises to a return to a golden age once the targeted enemy is thwarted. In the case of Germany in the 1930s it was the presumed overlapping categories of Jews and Bolsheviks, while in present day America and in Europe it is the immigrants and educated "elites."

Seymour Lipset summarizes findings from a UNESCO analysis of the relationship between voluntary association membership and German citizens' support for a one-party or multi-party political systems in the lead-up to the Nazis coming to power in Germany:

at every occupational level, those who belonged to voluntary associations were more likely to favor a multi-party system than a one-party one. American findings, too, indicate that authoritarians "do not join many community groups" as compared to non-authoritarians. And it has been discovered that people poorly informed on public issues are more likely to be both more liberal on economic issues and less liberal on noneconomic ones. Nonvoters and those less interested in political matters are more intolerant and xenophobic than those who vote and have political interests. (1981: 103, emphases in the original)

Lipset goes on to say that although intolerance typically has been found to be associated with lack of education, historically, it has been the lower middle class which has been attracted to Fascism. He argues that Fascism is an extreme variant of middle-class populism. According to Lipset, extreme right-wing movements arise when the lower middle class feels that its traditional status position has been threatened (1981: 131-7). At the same time, he notes that other classes have been attracted to Fascism under certain structural conditions. Thus, for example, large-scale industrialists, the core constituency of the conservative right, as well as significant portions of the church hierarchy were not among the original supporters of the Nazis, but they eventually col- 
laborated with them as they saw the rise of bolshevism in Russia and general secularization trends as threatening to their traditional status positions (Lipset 1981: 129). Most disturbing in this regard was the Vatican's decision, under Secretary of State Pacelli, later Pope Pius XII, to sign a concordat agreement with the Hitler government, ostensibly to protect Catholic Church interests in the Third Reich, but effectively neutralizing the countervailing power of the Catholic Center party, which was one of the last remaining powerful groups in opposition to Hitler (Cornwell 1999). This does not mean, of course, that these groups agreed with what the Nazis eventually did once they gained power, but it is fair to say that they were enablers, insofar as they removed serious obstacles without which the Third Reich perhaps might not have come to power in the first place.

The parallel between the supporters of Fascism in Germany in the 1930s and the rise of the Trump supporters in the United States is found in high levels of anxiety about status loss. The predecessor to the Trump phenomenon was the Tea Party Movement, whose supporters were not by any means the most economically deprived citizens, but was made up of white, especially small town and rural, Americans who felt that immigrants and racial/ethnic minorities were getting all of the advantages of government programs. This recent iteration of "populism" also has tremendous appeal for other segments of the voting public, especially the 81 percent of white Evangelical Christian and 60 percent of white Catholic Trump voters who railed against movements to protect the civil liberties of LGBT citizens and the rise of women in positions of influence in the workplace (Martinez and Smith 2016). This voting breakdown is consistent with Lipset's argument that, above all, Fascism is a "revolt against modernity" (1981: 488). Most telling is that once in office, Trump's appeals to his "base" largely focused on religious conservatives and xenophobic voters (Wilson-Hartgrove 2018).

The "revolt against modernity" is also reflected in the current rise of extreme right populism in Central and Eastern Europe. The clearest indicator of this is the fact that Poland and Hungary have experienced robust economic growth since the collapse of the Soviet Union and their integration into the European Union, and yet these nations have elected virulent anti-immigrant xenophobic governments that have actively sought to overturn liberal democratic institutions (Rohac 2018). The critical point, which is essential to understanding the main thesis of this book, is that all of these movements rest on the support of large segments of their populations who perceive that their traditional community attachments are under severe threat from conspiratorial outside influences.

While the increasing pace of technological change certainly has exacerbated the stress levels of large segments of the population, it is not the most economically distressed who support populist movements. Numerous studies of 
the Tea Party Movement and Trump voters have shown that even when they are in agreement with moderate voters on economic issues their fundamental rationale for supporting a right-wing candidate rests on culture and values, especially immigration, which is seen more as a threat to the traditional type of community they live in than a threat to their economic livelihood. Ironically, the perception of immigrants as a threat is often strong in rural regions which have experienced low levels of migrants, except in areas with meat processing plants, which offer jobs that are not attractive to white workers (DelReal and Clement 2017). Most important, 2016 election survey data showed that Trump voters, on average, had higher incomes than Clinton voters. This is explained by the fact that left-leaning American white voters tend to be more educated, but also much younger, and thus earlier in their careers than their more conservative fellow citizens (Chokshi 2018).

\section{COMMUNITY SUSTAINABILITY AND SUPPORT FOR LIBERAL DEMOCRATIC INSTITUTIONS}

The contemporary anxiety and subsequent resentment of individuals who perceive that their traditional communities have been threatened is, of course, a fertile environment for the rise of demagogues who articulate a clear target for those resentments, immigrants. But, the larger danger stemming from this perceived threat to the traditional community is an erosion of support for national political institutions.

\section{Trust in Government}

Tocqueville's (1858 [1955]) observation in the Old Regime and the French Revolution on the loss of support for the monarchy among the French peasants has some applicability to understanding the situation we face today with respect to declining support for liberal democratic institutions in the United States. He notes that the primary driver of discontent among the peasants was not economic per se, but rather the view that the monarchy was no longer on their side. In short, they believed that a traditional glue holding feudal society together, the obligations of the aristocratic class toward those in lower classes, the cultural norm of noblesse oblige, was no longer followed by their nobility.

If we think of the institutions of a liberal democratic society as serving a function that bears some similarity to that of the aristocracy in feudal society, insofar as their role is to provide a level of security for citizens in their day-to-day life, then it is concerning when trust in these institutions declines over time. Surveys have found that from 1973 to 2016, for example, there has been an overall erosion of support for various governmental institutions, including the Presidency and Congress. In 1964, three out of four Americans 
surveyed trusted their government to look out for their interests, but this level of trust declined to 33 percent of the sample in 1976 (Bishop 2017).

A closer look at specific institutional sectors presents a more nuanced picture of the way in which some social categories of individuals have been more affected than others by a perceived challenge to their traditional community culture and social organizations, with a corresponding differentiation between them with respect to their anxiety and resentment toward liberal democratic institutions. Specifically, it is the emergence of the extreme right and its apparent takeover of the once center-right Republican Party that has been most critical of liberal democratic institutions. Surveys of Tea Party members and Trump supporters have found the most extreme versions of the view that somehow "the government" is not on their side, and that other "less deserving" groups, such as racial minorities, Latinos and Muslims receive favorable treatment. This, in turn, has led to distrust of traditional institutional supports of liberal democracy, especially the so-called "mainstream media," which has been labeled as "fake news," and the rise of conspiracy theories about "the deep state," the perjorative term for the government civil service (Chokshi 2018; McBain 2017; Pew Research Center 2011). Most disturbing is that this distrust has spread to science.

\section{Trust in Science}

A similar ideological opposition is found in resistance to scientific facts that confirm the need to regulate emissions that contribute to global climate change and its associated health and economic costs (Hoffman 2012). More recently, this has been expressed in conservatives' resistance to wearing masks in public during the Covid-19 virus epidemic (Kamisar and Holzberg 2020).

A study of Americans' "trust in science," using General Social Survey (GSS) data from 1974 to 2010, shows that in 1974 self-identified conservatives had the highest level of trust in science, but increasingly over time became the most distrustful. Moreover, this relationship held among the most educated individuals with a conservative political orientation (Gauchat 2012).

The resistance of individuals, all individuals, to change their views when a change is perceived to be a threat to something in which they have made a significant personal investment has been explained in numerous experiments under the general rubric of "cognitive dissonance theory" (Festinger 1962). Scientific information that threatens strongly held beliefs is especially challenging in this regard and affects persons on the extreme left as well, as evidenced by the anti-vaccination movement in the United States (Gawande 2016). Karl Popper's (2013) classic statement on the principle of "falsifiability" as the cornerstone of science was especially critical of Marxist intellectu- 
als, who at the time of its original publication in 1945 were making assertions about history and the future without any empirical basis.

The most important implication of the proceeding is that overcoming resistance to the changes that are necessary to more effectively provide public goods with respect to a sustainable natural environment, workforce development, health and mental health, requires first an understanding of the underlying source of resistance. Our thesis is that the underlying cause of resistance to change that harms the larger public is the fear that one's attachment to a traditional community, be it real or imagined, is not being addressed in an empathetic way.

\section{FORMAL INSTITUTIONAL SOLUTIONS TO PERCEIVED "COMMUNITY THREAT"}

The task of this book is to address these underlying "community threat" issues and to provide practical formal institutional solutions to them. Fortunately, similar issues have emerged at earlier times in history. The specifics, of course, change from one era to another, and thus require novel solutions. But, it would be the height of arrogance to suggest that the community issues facing us today are in any way more serious for us than to those living with the anxiety generated by the Renaissance, the Reformation, the Enlightenment and the Industrial Revolution. All of these periods involved monumental change in technology and ways of looking at the world, which generated extreme anxiety in the lives of ordinary people. As Erich Fromm (1965) reminds us, the serf may have gained "freedom" when the feudal order collapsed, but he also lost "his place" in life and with it a connection to a much larger gestalt. His poignant statement in Escape from Freedom, published in 1941, in the midst of the horrors of World War II, is especially relevant today. He says,

Contrary to Freud's viewpoint, the analysis offered in this book is based on the assumption that the key problem of psychology is that of the specific kind of relatedness of the individual towards the world and not that of the satisfaction or frustration of this or that instinctual need per se; furthermore, on the assumption that the relationship between man and society is not a static one... The most beautiful as well as the most ugly inclinations of man are not part of a fixed and biologically given human nature, but result from the social process which creates man. (1965: 26-7, my emphasis)

Given the more than three-quarter century advances in scientific knowledge of biological processes and how they affect human thinking and behavior, we are not as likely to accept Fromm's rather extreme view of how much human beings are shaped by their social environment. Nonetheless, his assertion about the centrality of connectedness, especially connectedness to community is as 
true today as it was in the 1940s. The critical point is that human beings can find ways to create institutions that will alleviate the anxiety of those living through periods of major structural change. Eventually, after many years of horrible human suffering new formal institutional arrangements to deal with the impact of these technological changes have been effectively implemented in many places throughout the globe. Some type of social safety net and institutions to provide peaceful ways of handling international disputes, as well as a variety of health and safety regulations have become more widely accepted. As Steven Pinker (2018) reminds us, the arc of history has in fact been more positive over time as humans have found ways to solve problems and improve the quality of life of ordinary people.

The motivation in writing this book is based on the assumption that practical institutional solutions to community issues, and their attendant effects on larger public goods challenges, can be implemented. Before specifying these solutions, however, it is necessary for us to examine in more detail the sources of resistance to changing our approaches to these problems. This is the subject of the next chapter. 